\title{
Outcomes in COVID-19 Positive Neonates and Possibility of Viral Vertical Transmission: A Narrative Review
}

\author{
Sudip Sheth, MD, MPH ${ }^{1, *(0)}$ Nidhi Shah, $\mathrm{MD}^{2, *}$ Vineet Bhandari, MD, $\mathrm{DM}^{3}$ \\ ${ }^{1}$ Division of Neonatology, Department of Pediatrics, Texas Tech \\ Address for correspondence Vineet Bhandari, MD, DM, Head, \\ University Health Sciences Center, Odessa, Texas \\ 2 Department of Pediatrics, Greater Philadelphia Health Action \\ (GPHA), Philadelphia, Pennsylvania \\ Division of Neonatology, The Children's Regional Hospital at Cooper, \\ One Cooper Plaza, Camden, NJ 08103 \\ (e-mail: bhandari-vineet@cooperhealth.edu).
}

3 Division of Neonatology, Department of Pediatrics, The Children's

Regional Hospital at Cooper, Cooper Medical School of Rowan

University, Camden, New Jersey

Am J Perinatol 2020;37:1208-1216.

\section{Abstract}

Keywords

- COVID-19

- novel coronavirus 2019

- SARS-CoV-2

- neonates

- neonatal outcomes

- vertical transmission

Objective Novel coronavirus disease 2019 (COVID-19) seems to affect adults and pediatric patients differently. While neonates are a special population, little is known about the neonatal outcomes. This study aimed to investigate the outcomes in COVID-19 positive neonates and incidence of vertical transmission of the virus by reviewing available literature.

Study Design This study is a narrative review of available literature on "COVID-19 in neonates," for which PubMed and Google Scholar were used to search the published articles. Results We summarized the data from 39 published studies that are comprised of 326 COVID-19 positive peripartum mothers with respective neonatal outcomes. Twenty-three neonates have been reported to be COVID-19 positive. Male neonates were affected significantly more (79\%) than female neonates. Approximately $3 \%$ neonates acquired infection through suspected vertical transmission. Strict infection prevention measures during the perinatal time can significantly reduce the chance of horizontal transmission of the virus. Overall, neonates were asymptomatic or mildly symptomatic regardless of gestational age at birth and required only supportive measures. There was $0 \%$ mortality in COVID-19 positive neonates.

Conclusion From available published data to date, we can conclude that the prognosis of COVID-19 positive neonates is good with no mortality. There appears to be minimal vertical transmission of the infection.
\end{abstract}

\section{Key Points}

- Majority of COVID-19 positive neonates showed mild clinical signs and symptoms with no mortality.

- Most COVID-19 positive neonates require only supportive measures.

- Possibility of viral vertical transmission is very low.

\footnotetext{
* These authors contributed equally to this work.
}

received

June 2, 2020

accepted after revision

July 7, 2020

published online

July 31,2020
Copyright $\odot 2020$ by Thieme Medical

Publishers, Inc., 333 Seventh Avenue, New York, NY 10001, USA Tel: $+1(212) 760-0888$.
DOI https://doi.org/ 10.1055/s-0040-1714719. ISSN 0735-1631. 
It has been $>6$ months since the first case of novel coronavirus disease 2019 (COVID-19) was identified in Wuhan, China, ${ }^{1}$ and $>4$ months since the World Health Organization (WHO) announced COVID-19 as a pandemic. ${ }^{2}$ While medical communities over the entire world are learning about this new virus including pathogenesis, prevention, and treatment, there has been significant morbidities and mortalities all over the world. As of June 18,2020 , there are 8,242,999 confirmed cases and 445,535 deaths worldwide due to COVID-19. ${ }^{3}$

The overall understanding is that this disease is more dangerous in adults with increasing age along with comorbidities, compared with children. ${ }^{4}$ There have been a few studies focused on understanding the clinical characteristics in the pediatric population. ${ }^{4-7}$ Neonates are a special population in pediatrics who might have different level of risks and susceptibilities compared with the older pediatric population.

There have been multiple case reports, case series, and retrospective studies published regarding maternal transmission of COVID-19 to their newborns vertically and horizontally, as well as the morbidities in COVID-19 positive neonates. $^{8-46}$ This narrative review is to summarize the clinical characteristics of COVID-19 positive neonates and to investigate the possibility of vertical transmission of COVID-19 positive mothers to their newborns from published data to date (June 18, 2020).

\section{Materials and Methods}

We searched published articles in English language only through PubMed and Google Scholar with search terms such as "novel coronavirus," "COVID-19," "SARS-CoV-2," along with "neonate," "newborn," and "vertical transmission." We searched articles from November 15, 2019, through June 18, 2020. A total of 304 studies were retrieved. Articles were screened for COVID-19 reverse-transcriptase-polymerase chain reaction (RT-PCR)-positive and -negative neonates, COVID-19 positive or -negative pregnant women, sex, gestational age (GA) at birth, clinical findings, management, outcome, and possibility of vertical versus horizontal transmission. Finally, we included 39 studies, ${ }^{8-46}$ which reported COVID-19 positive and/or negative neonates, regardless of the number of the COVID-19 positive mothers.

We only included the studies in our data table that reported outcomes of neonates ( $<28$ days of life), regardless of GA at birth. We divided all the studies in three different sections as follows: (1) case reports, which reported only single cases of COVID-19 positive neonates; (2) case series or retrospective review, which reported $\geq 1$ COVID-19 positive neonates; and (3) case series or retrospective review, which reported $\geq 1$ COVID-19 positive mother with zero neonatal cases. We only included the single-center study data to avoid the risk of overlapping data with multihospital data registries.

\section{Definitions}

We defined "COVID-19 positive neonate" only if he/she had a positive severe acute respiratory syndrome-coronavirus-2 (SARS-CoV-2) quantitative RT-PCR test in a nasopharyngeal sample. We considered a "COVID-19 positive mother" if she had a positive SARS-CoV-2 quantitative RT-PCR test in a nasopharyngeal sample during the peripartum period. "Infection prevention measures during the delivery" was mentioned if the baby was delivered in an isolation room and/or with personal protective equipment being worn by delivery staff and the baby was immediately isolated from the mother after delivery. Vertical transmission refers to the passage of a pathogen from mother to baby during the period before birth, while horizontal transmission refers to the passage of pathogen from an infected person to the baby after birth by either direct or indirect contact.

\section{Results}

-Table 1 illustrates the summary of 10 case reports, which reported only single cases of COVID-19 positive neonates, while - Table 2 presents the summary of 7 case series and/or retrospective review, which reported $\geq 1$ COVID-19 positive neonates. Both tables include the clinical presentation in the mother, mode of delivery, demographic characteristics of the neonate, age at diagnosis in the neonate, possible route of transmission, clinical/radiographical/laboratory findings, required management, and mortality. - Table 3 includes 22 studies with $\geq 1$ COVID-19 positive mother with no neonatal cases.

Overall, 23 neonates have been reported as COVID-19 positive till date (June 18, 2020), out of which 10 acquired infection through suspected vertical transmission. In all the studies, the total number of positive COVID-19 mothers were 326 , so approximately $3 \%$ of the babies were born with some chances of vertical transmission. Six out of 20 (30\%) were preterm neonates, while one study did not mention the GA at birth. ${ }^{21}$ Eight out of 23 (35\%) were diagnosed as late onset ( $>7$ days of life) infection. Interestingly, 15 out of 19 (79\%) were male neonates as two studies did not mention the sex of total four neonates who were COVID-19 positive. ${ }^{19,30}$ The overall clinical presentation was asymptomatic to mild symptoms without any mortality. Three out of 23 (13\%) required mechanical ventilation, but 2 out of those 3 neonates had additional contributing factors that could have accounted for the presence of respiratory distress.

\section{Discussion}

As the entire world is learning about COVID-19 virus, there has been sparse information available, to date, regarding neonates. We attempted to gather knowledge regarding neonatal clinical characteristics from currently published case series and case reports. To the best of our knowledge, we have reviewed one of the largest study population of 326 COVID-19 positive mothers with respective neonatal outcomes.

Though SARS-CoV-2 quantitative RT-PCR test has low sensitivity, it is still a gold-standard test at this time. ${ }^{47,48}$ However, the availability of this test is limited as it is time consuming and requires specialized operators. Rapid antibody/ serological tests have been available but are not recommended at this time to diagnose acute infection in neonates as per the 


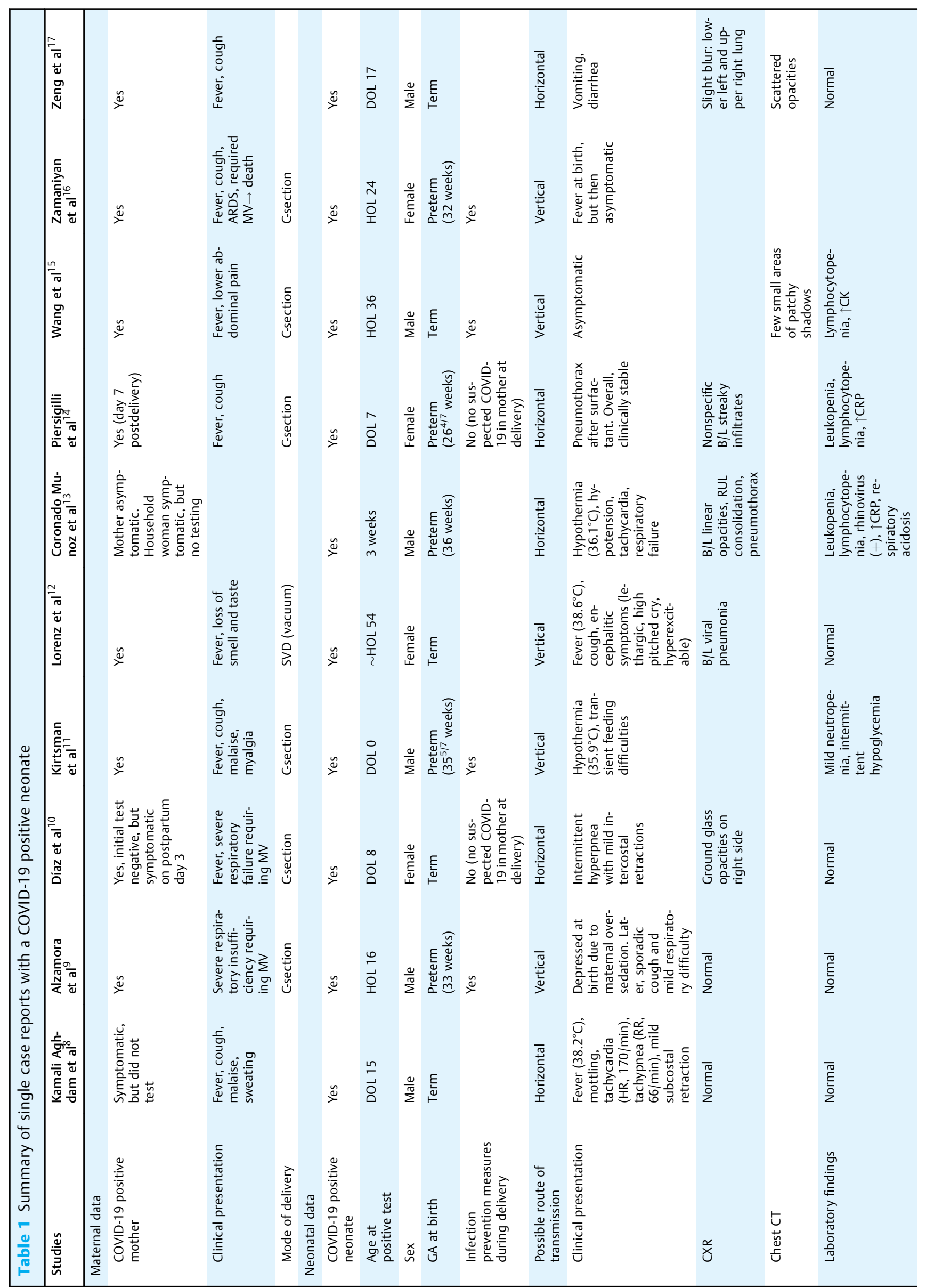



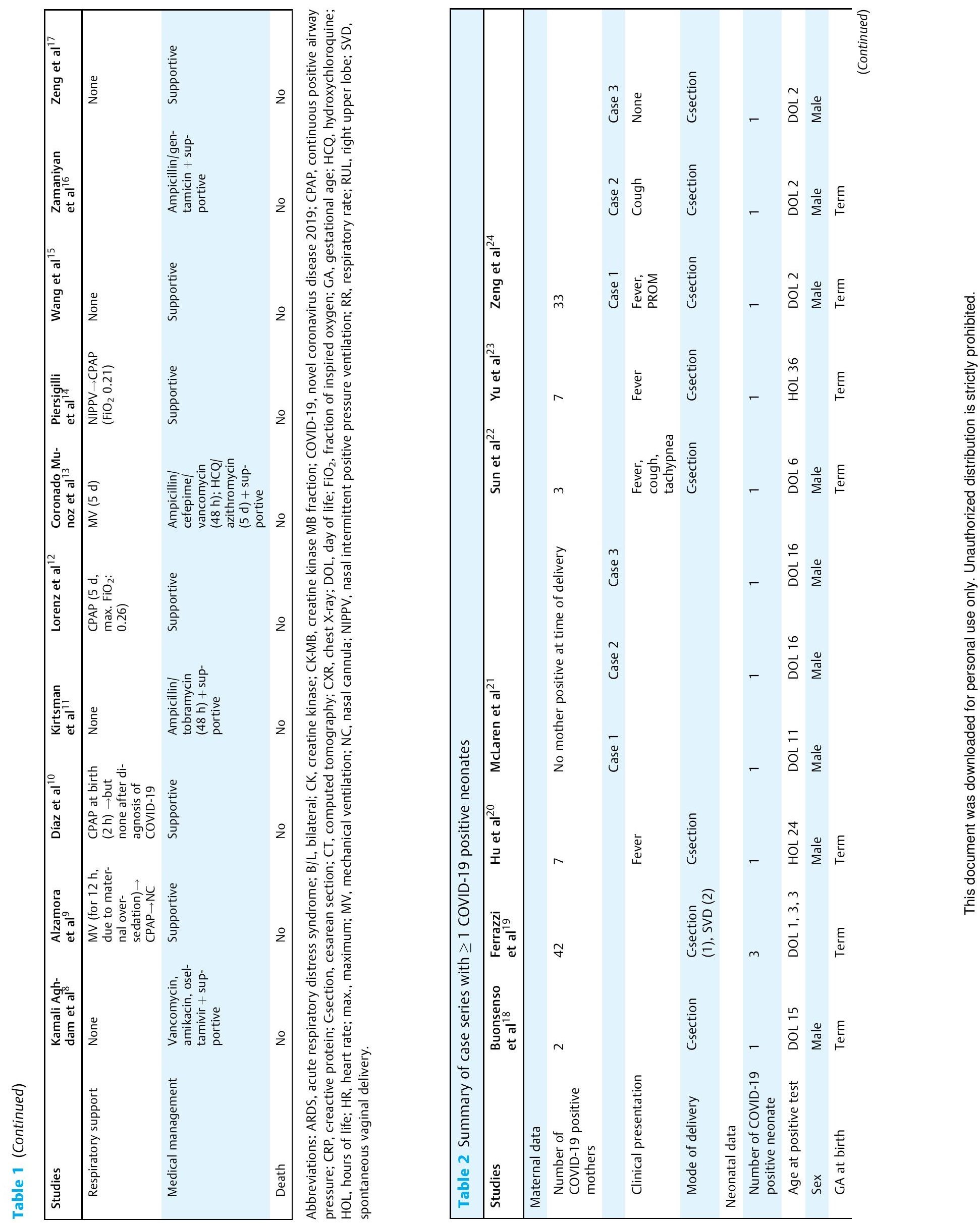


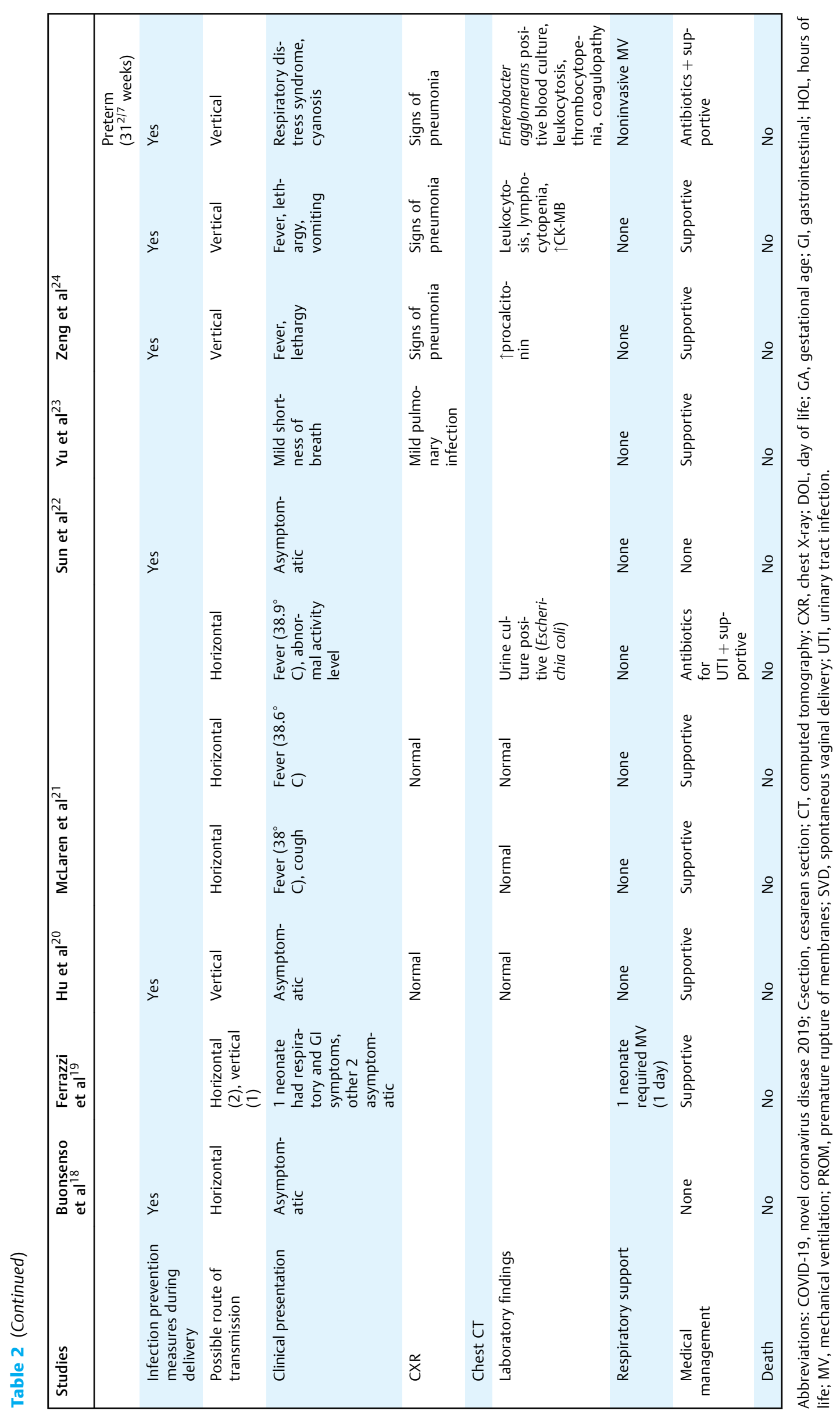


Table 3 Summary of studies with $\geq 1$ COVID-19 positive mothers with zero neonatal cases

\begin{tabular}{|c|c|c|}
\hline Studies & $\begin{array}{l}\text { Number of } \\
\text { COVID-19 positive } \\
\text { mothers }\end{array}$ & $\begin{array}{l}\text { Number of } \\
\text { COVID-19 positive } \\
\text { neonates }\end{array}$ \\
\hline Algarroba et al ${ }^{25}$ & 1 & 0 \\
\hline Baergen et $\mathrm{al}^{26}$ & 20 & 0 \\
\hline Breslin et $\mathrm{a}^{27}$ & 43 & 0 \\
\hline Chen et $\mathrm{al}^{28}$ & 4 & 0 \\
\hline Chen et $\mathrm{al}^{29}$ & 9 & 0 \\
\hline Chen et $\mathrm{al}^{30}$ & 17 & 0 \\
\hline Dong et $\mathrm{al}^{31}$ & 1 & 0 \\
\hline Griffin et $\mathrm{al}^{32}$ & 14 & 0 \\
\hline Jain et $\mathrm{al}^{33}$ & 2 & 0 \\
\hline Khan et $\mathrm{al}^{34}$ & 3 & 0 \\
\hline Lee at $\mathrm{al}^{35}$ & 1 & 0 \\
\hline Li et $\mathrm{al}^{36}$ & 1 & 0 \\
\hline Li et $\mathrm{al}^{37}$ & 16 & 0 \\
\hline Liu et $\mathrm{al}^{38}$ & 19 & 0 \\
\hline Lowe and Bopp 39 & 1 & 0 \\
\hline Penfield et al ${ }^{40}$ & 32 & 0 \\
\hline $\begin{array}{l}\text { Qiancheng } \\
\text { et al }{ }^{41}\end{array}$ & 22 & 0 \\
\hline Wang et al ${ }^{42}$ & 1 & 0 \\
\hline Xiong et al ${ }^{43}$ & 1 & 0 \\
\hline Zambrano et al ${ }^{44}$ & 1 & 0 \\
\hline Zeng et $\mathrm{al}^{45}$ & 6 & 0 \\
\hline Zhu et al ${ }^{46}$ & 9 & 0 \\
\hline
\end{tabular}

Abbreviation: COVID-19, novel coronavirus disease 2019.

Centers for Disease Control and Prevention (CDC) due to its limitations. ${ }^{48,49}$ If a neonate of the COVID-19 positive mother cannot be tested, then he/she should be treated as if virus positive for the 14-day period of observation and the mother should still maintain precautions until she meets the criteria for noninfectivity as per the recommendation by the American Academy of Pediatrics (AAP). ${ }^{50}$

In studies by Dong et al and Zeng et al, immunoglobulin (Ig)-M levels were increased in three neonates. ${ }^{31,45}$ They speculated that the elevated IgM antibody level may suggest that the neonate was infected in utero, as IgM does not transfer through placenta but RT-PCR was repeatedly negative on all three neonates in both studies. In response to these two studies, Kimberlin et al mentioned significant limitations of diagnosing any congenital infection on the basis of IgM levels. With limited knowledge about the COVID-19 infection, they cautioned against interpreting these results in favor of in-utero transmission. ${ }^{51}$ Elevated IgG level in the same studies can suggest transfer of passive immunity from the mother against COVID-19.

Interestingly, male neonates were affected significantly more than female neonates, which was a similar observation in a review by Yagnik et al. ${ }^{52}$ Seven neonates out of 23 (30\%) were asymptomatic, while common clinical findings in symptomatic neonates were fever $\left(38-39^{\circ} \mathrm{C}\right)$, lethargy, tachycardia, hypotension, respiratory symptoms (tachypnea and mild intercostal/subcostal retractions), and gastrointestinal symptoms (vomiting and/or diarrhea). Interestingly neonates were observed to be sicker if they had suspected horizontal transmission versus vertical transmission. ${ }^{8,13,17}$ Coronado et al presented a 3-week-old neonate with severe respiratory failure requiring mechanical ventilation, who was also positive for rhinovirus, which can be a major confounding factor for the illness. ${ }^{13,53}$ As per Alzamora et al, the newborn required intubation/mechanical ventilation possibly due to maternal oversedation and was extubated around 12 hours of life (HOL) without any issues. ${ }^{9}$ As per Zeng et al, the newborn required intubation and mechanical ventilation possibly due to prematurity (31 weeks) and suspected sepsis due to Enterobacter agglomerans positive blood culture. ${ }^{24}$ Lorenz et al observed encephalopathic symptoms in a neonate with COVID-19, which resolved with supportive measures. The sample from cerebrospinal fluid (CSF) was negative for COVID-19 RT-PCR. ${ }^{12}$ Laboratory findings were mostly normal, while some neonates showed leukopenia/leukocytosis, lymphocytopenia, and increased inflammatory markers. Chest X-ray findings were mostly nonspecific, while some studies showed signs of pneumonia. Most of the neonates were managed with supportive care. Fortunately, no deaths were reported in COVID-19 positive neonates.

Few studies reported premature births suspected due to infection in COVID-19 positive mothers. ${ }^{19,37,46}$ As per Zhu et al, 6 out of 10 neonates were born premature. The neonates presented with all the above mentioned symptoms along with one death, but none of the neonates had a positive RTPCR test. ${ }^{46}$ The possibility of false negative tests cannot be ruled out. They also speculated that COVID-19 infection in mothers may cause hypoxemia, therefore increasing the risk of perinatal adverse events such as birth asphyxia and premature birth. One more speculation might be the placental insufficiency. Li et al also observed increased preterm deliveries in COVID-19 positive or-suspected mothers, while they indicated the possible explanation being gestational complications, such as premature rupture of membranes and placental bleeding, which might not be directly related to COVID-19 pneumonia. ${ }^{37}$

In most studies, vertical transmission was suspected if a neonate was tested positive for COVID-19 RT-PCR within the first $48 \mathrm{HOL}$ in presence of infection prevention measures in place during delivery. Out of 326 COVID-19 positive mothers, there were only $10(3 \%)$ neonates that possibly acquired the virus through vertical transmission, which in fact were not proven. Algarroba et al showed potential viral transmission in the placenta by identifying coronavirus virions in placental villi using electron microscopy, but the newborn was COVID-19 RT-PCR negative and asymptomatic. ${ }^{25}$ So, from these limited data we agree with Mimouni et al that vertical transmission from maternal infection to fetus probably occurs rarely. ${ }^{54}$ Currently, AAP recommends testing the 
newborns born to COVID-19 positive mothers at approximately 24 and 48 HOL. $^{50}$

Rawat et al speculate on why neonates have been spared of COVID-19 serious symptomatology, but also caution that they can be carriers for transmission of the virus to vulnerable adults. ${ }^{55}$ In addition to that, there is scarce information about the short- and long-term effects of infection on neonates. Therefore, it is vital to prevent infection in the neonates. Several publications have suggested steps to be taken to prevent horizontal transmission during neonatal resuscitation at delivery of COVID-19 positive mothers. ${ }^{56-58}$ On that basis, AAP recommends to wear personal protective equipment including a gown, gloves, N95 respiratory mask, and eye protection goggles or an air-purifying respirator that provides eye protection while attending deliveries or conducting neonatal resuscitation for neonates born to COVID19 positive mothers. ${ }^{50}$ Delayed cord clamping has not been shown to transmit the virus as yet, and so it should be continued as per the unit policy. ${ }^{32,50}$ The transmission through skin-to-skin contact is controversial, and hence, skin-to-skin contact can be allowed by the mother using facemasks and hand hygiene. ${ }^{32,50,56}$

As per current evidence, the virus is not transmitted via breast milk, ${ }^{15,29}$ and so the benefits of breastfeeding outweigh the potential risk of infection transmission. Chandrasekharan et al recommend three different approaches to feed the baby as follows: (1) complete isolation and feeding formula/donor breast milk, (2) feed the expressed breast milk after taking strict precautions, or (3) breastfeeding with strict precautions. ${ }^{56}$ The authors also suggest, it would be best practice to discuss with parents regarding these precautions before delivery and help them to participate in decision making. Most studies included in -Tables 1-3 describe their infection prevention control strategies during delivery, which seem to prevent horizontal viral transmission significantly regardless of GA at birth.

In the home environment, the mother should try to maintain a distance of at least 6 feet when possible, use a face mask, and have hand hygiene along with above recommendations during feeding after discharge from the hospital. This can be accomplished by a thorough verbal education of the parents as per AAP. ${ }^{50,59}$ As per CDC, if a neonate starts showing symptoms, other diagnoses for example, neonatal sepsis, influenza, should also be considered along with the diagnosis of COVID-19 and tested as per the availability. ${ }^{60}$

We included studies from different countries including China, Korea, India, Italy, Spain, Belgium, Germany, France, Australia, the United States, Canada, Iran, Peru, Honduras, and Brazil. The majority of the studies are from Wuhan, China, and so it is possible that there might be some overlap in the patient population, although we avoided including any studies from the national/local registries.

National Registry for Surveillance and Epidemiology of Perinatal COVID-19 Infection (NPC-19 Registry) in the United States has received information of 911 mother/infant dyads from 190 participating centers as of June 12, 2020, which has 30 infants positive for COVID-19. We look forward to have more insight into the outcomes of COVID-19 positive neonates and possibility of viral vertical transmission when the study is published. ${ }^{61}$

\section{Conclusion}

Majority of COVID-19 positive neonates showed mild clinical signs and symptoms with no mortality. Most neonates required only supportive measures. Interestingly, males were affected significantly more than females. Possibility of vertical transmission is very low and horizontal transmission appears to have been prevented with strict infection prevention measures during delivery regardless of GA age at birth. This review is based on current limited literature. As the pandemic continues, there will be more data available that could lead to significant changes in the current associations and recommendations.

\section{Conflict of Interest}

None declared.

\section{References}

1 The first COVID-19 case originated on November 17, according to Chinese officials searching for "Patient Zero." Available at: https:// www.msn.com/en-us/news/world/the-first-covid-19-case-originated-on-november-17-according-to-chinese-officials-searchingfor-patient-zero/ar-BB119fWJ. Accessed June 18, 2020

2 World Health Organization. WHO Director-General's opening remarks at the media briefing on COVID-19: 11 March 2020. Available at: https://www.who.int/dg/speeches/detail/who-director-general-s-opening-remarks-at-the-media-briefing-on-covid19-11-march-2020. Accessed June 18, 2020

3 World Health Organization coronavirus disease (COVID-19) dashboard. Available at: https://covid19.who.int/. Accessed June 18, 2020

4 Dong Y, Mo X, Hu Y, et al. Epidemiology of COVID-19 among children in China. Pediatrics 2020;145(06):e20200702

5 Lu X, Zhang L, Du H, et al; Chinese Pediatric Novel Coronavirus Study Team. SARS-CoV-2 infection in children. N Engl J Med 2020; 382(17):1663-1665

6 Xu Y, Li X, Zhu B, et al. Characteristics of pediatric SARS-CoV-2 infection and potential evidence for persistent fecal viral shedding. Nat Med 2020;26(04):502-505

7 Hageman JR. The coronavirus disease 2019 (COVID-19). Pediatr Ann 2020;49(03):e99-e100

8 Kamali Aghdam M, Jafari N, Eftekhari K. Novel coronavirus in a 15day-old neonate with clinical signs of sepsis, a case report. Infect Dis (Lond) 2020;52(06):427-429

9 Alzamora MC, Paredes T, Caceres D, Webb CM, Valdez LM, La Rosa M. Severe COVID-19 during pregnancy and possible vertical transmission. Am J Perinatol 2020;37(08):861-865

10 Díaz CA, Maestro ML, Pumarega MTM, Antón BF, Alonso CP. [First case of neonatal infection due to COVID 19 in Spain] (in Spanish). An Pediatr (Engl Ed) 2020;92(04):237-238

11 Kirtsman M, Diambomba Y, Poutanen SM, et al. Probable congenital SARS-CoV-2 infection in a neonate born to a woman with active SARS-CoV-2 infection. CMAJ 2020;192(24):E647-E650

12 Lorenz N, Treptow A, Schmidt S, et al. Neonatal early-onset infection with SARS-CoV-2 in a newborn presenting with encephalitic symptoms. Pediatr Infect Dis J 2020 (e-pub ahead of print). Doi: 10.1097/INF.0000000000002735

13 Coronado Munoz A, Nawaratne U, McMann D, Ellsworth M, Meliones J, Boukas K. Late-onset neonatal sepsis in a patient with COVID-19. N Engl J Med 2020;382(19):e49 
14 Piersigilli F, Carkeek K, Hocq C, et al. COVID-19 in a 26-week preterm neonate. Lancet Child Adolesc Health 2020;4(06): 476-478

15 Wang S, Guo L, Chen L, et al. A case report of neonatal COVID-19 infection in China. Clin Infect Dis 2020 (e-pub ahead of print). Doi: $10.1093 /$ cid/ciaa225

16 Zamaniyan M, Ebadi A, Aghajanpoor Mir S, Rahmani Z, Haghshenas M, Azizi S. Preterm delivery in pregnant woman with critical COVID-19 pneumonia and vertical transmission. Prenat Diagn 2020 (e-pub ahead of print). Doi: 10.1002/pd.5713

17 Zeng LK, Tao XW, Yuan WH, Wang J, Liu X, Liu ZS. [First case of neonate with COVID-19 in China]. Zhonghua Er Ke Za Zhi 2020;58 (04):279-280

18 Buonsenso D, Costa S, Sanguinetti M, et al. Neonatal late onset infection with severe acute respiratory syndrome coronavirus 2 . Am J Perinatol 2020;37(08):869-872

19 Ferrazzi E, Frigerio L, Savasi V, et al. Vaginal delivery in SARS-CoV2-infected pregnant women in Northern Italy: a retrospective analysis. BJOG 2020 (e-pub ahead of print). Doi: 10.1111/14710528.16278

$20 \mathrm{Hu} X$, Gao J, Luo X, et al. Severe acute respiratory syndrome coronavirus 2 (SARS-CoV-2) vertical transmission in neonates born to mothers with coronavirus disease 2019 (COVID-19) pneumonia. Obstet Gynecol 2020;136(01):65-67

21 McLaren SH, Dayan PS, Fenster DB, et al. Novel coronavirus infection in febrile infants aged 60 days and younger. Pediatrics 2020 (e-pub ahead of print). Doi: 10.1542/peds.2020-1550

22 Sun M, Xu G, Yang Y, et al. Evidence of mother-to-newborn infection with COVID-19. Br J Anaesth 2020 (e-pub ahead of print). Doi: 10.1016/j.bja.2020.04.066

23 Yu N, Li W, Kang Q, et al. Clinical features and obstetric and neonatal outcomes of pregnant patients with COVID-19 in Wuhan, China: a retrospective, single-centre, descriptive study. Lancet Infect Dis 2020;20(05):559-564

24 Zeng L, Xia S, Yuan W, et al. Neonatal early-onset infection with SARS-CoV-2 in 33 neonates born to mothers with COVID-19 in Wuhan, China. JAMA Pediatr 2020 (e-pub ahead of print). Doi: 10.1001/jamapediatrics.2020.0878

25 Algarroba GN, Rekawek P, Vahanian SA, et al. Visualization of SARS-CoV-2 virus invading the human placenta using electron microscopy. Am J Obstet Gynecol 2020 (e-pub ahead of print). Doi: 10.1016/j.ajog.2020.05.023

26 Baergen RN, Heller DS. Placental pathology in COVID-19 positive mothers: preliminary findings. Pediatr Dev Pathol 2020;23(03): 177-180

27 Breslin N, Baptiste C, Gyamfi-Bannerman C, et al. COVID-19 infection among asymptomatic and symptomatic pregnant women: two weeks of confirmed presentations to an affiliated pair of New York City hospitals. Am J Obstet Gynecol MFM 2020;2(02):100118; (epub ahead of print). Doi: 10.1016/j.ajogmf.2020.100118

28 Chen Y, Peng H, Wang L, et al. Infants Born to Mothers With a New Coronavirus (COVID-19). Front Pediatr 2020;8:104

29 Chen H, Guo J, Wang C, et al. Clinical characteristics and intrauterine vertical transmission potential of COVID-19 infection in nine pregnant women: a retrospective review of medical records. Lancet 2020;395(10226):809-815

30 Chen R, Zhang Y, Huang L, Cheng BH, Xia ZY, Meng QT. Safety and efficacy of different anesthetic regimens for parturients with COVID-19 undergoing Cesarean delivery: a case series of 17 patients. Can J Anaesth 2020;67(06):655-663

31 Dong L, Tian J, He S, et al. Possible vertical transmission of SARSCoV-2 from an infected mother to her newborn. JAMA 2020 (epub ahead of print). Doi: 10.1001/jama.2020.4621

32 Griffin I, Benarba F, Peters C, et al. The impact of COVID-19 infection on labor and delivery, newborn nursery, and neonatal intensive care unit: prospective observational data from a single hospital system. Am J Perinatol 2020 (e-pub ahead of print). Doi: $10.1055 / \mathrm{s}-0040-1713416$
33 Jain P, Thakur A, Kler N, Garg P. Manifestations in neonates born to COVID-19 positive mothers. Indian J Pediatr 2020 (e-pub ahead of print). Doi: 10.1007/s12098-020-03369-x

34 Khan S, Peng L, Siddique R, et al. Impact of COVID-19 infection on pregnancy outcomes and the risk of maternal-to-neonatal intrapartum transmission of COVID-19 during natural birth. Infect Control Hosp Epidemiol 2020;41(06):748-750

35 Lee DH, Lee J, Kim E, Woo K, Park HY, An J. Emergency cesarean section on severe acute respiratory syndrome coronavirus 2 (SARS- CoV-2) confirmed patient. Korean J Anesthesiol 2020 (epub ahead of print). Doi: 10.4097/kja.20116

36 Li Y, Zhao R, Zheng S, et al. Lack of vertical transmission of severe acute respiratory syndrome coronavirus 2, China. Emerg Infect Dis 2020;26(06):1335-1336

37 Li N, Han L, Peng M, et al. Maternal and neonatal outcomes of pregnant women with COVID-19 pneumonia: a case-control study. Clin Infect Dis 2020 (e-pub ahead of print). Doi: 10.1093/cid/ ciaa352

38 Liu W, Wang J, Li W, Zhou Z, Liu S, Rong Z. Clinical characteristics of 19 neonates born to mothers with COVID-19. Front Med 2020; 14(02):193-198

39 Lowe B, Bopp B. COVID-19 vaginal delivery - A case report. Aust N Z J Obstet Gynaecol 2020;60(03):465-466

40 Penfield CA, Brubaker SG, Limaye MA, et al. Detection of SARSCOV-2 in placental and fetal membrane samples. Am J Obstet Gynecol MFM 2020 (e-pub ahead of print). Doi: 10.1016/j. ajogmf.2020.100133

41 Qiancheng X, Jian S, Lingling P, et al; sixth batch of Anhui medical team aiding Wuhan for COVID-19. Coronavirus disease 2019 in pregnancy. Int J Infect Dis 2020;95:376-383

42 Wang X, Zhou Z, Zhang J, Zhu F, Tang Y, Shen X. A case of 2019 Novel Coronavirus in a pregnant woman with preterm delivery. Clin Infect Dis 2020 (e-pub ahead of print). Doi: 10.1093/cid/ ciaa200

43 Xiong X, Wei H, Zhang Z, et al. Vaginal delivery report of a healthy neonate born to a convalescent mother with COVID-19. J Med Virol 2020 (e-pub ahead of print). Doi: 10.1002/jmv.25857

44 Zambrano LI, Fuentes-Barahona IC, Bejarano-Torres DA, et al. A pregnant woman with COVID-19 in Central America. Travel Med Infect Dis 2020 (e-pub ahead of print). Doi: 10.1016/j. tmaid.2020.101639

45 Zeng $\mathrm{H}, \mathrm{Xu} \mathrm{C}$, Fan J, et al. Antibodies in infants born to mothers with COVID-19 pneumonia. JAMA 2020 (e-pub ahead of print). Doi: $10.1001 /$ jama.2020.4861

46 Zhu H, Wang L, Fang C, et al. Clinical analysis of 10 neonates born to mothers with 2019-nCoV pneumonia. Transl Pediatr 2020;9 (01):51-60

47 Dramé M, Teguo MT, Proye E, et al. Should RT-PCR be considered a gold standard in the diagnosis of Covid-19? J Med Virol 2020 (epub ahead of print). Doi: 10.1002/jmv.25996

48 Cassaniti I, Novazzi F, Giardina F, et al; Members of the San Matteo Pavia COVID-19 Task Force. Performance of VivaDiag COVID-19 IgM/IgG rapid test is inadequate for diagnosis of COVID-19 in acute patients referring to emergency room department. J Med Virol 2020 (e-pub ahead of print). Doi: 10.1002/jmv.25800

49 CDC. Using antibody tests for COVID-19. Available at: https:// www.cdc.gov/coronavirus/2019-ncov/lab/resources/antibodytests.html. Accessed on June 18, 2020

50 FAQs: management of infants born to mothers with suspected or confirmed COVID-19. Available at: https://services.aap.org/en/ pages/2019-novel-coronavirus-covid-19-infections/clinicalguidance/faqs-management-of-infants-born-to-covid-19-mothers/. Accessed on June 18, 2020

51 Kimberlin DW, Stagno S. Can SARS-CoV-2 infection be acquired in utero?: More definitive evidence is needed JAMA 2020 (e-pub ahead of print). Doi: 10.1001/jama.2020.4868

52 Yagnik PJ, Umscheid J, Khan AW, Ali M, Bhatt P, Desai PH. Pediatric characteristics of 2019 novel coronavirus: review of available 
published literature. Clin Pediatr (Phila) 2020 (e-pub ahead of print). Doi: 10.1177/0009922820920017

53 Peltola V, Waris M, Osterback R, Susi P, Hyypiä T, Ruuskanen O. Clinical effects of rhinovirus infections. J Clin Virol 2008;43(04): 411-414

54 Mimouni F, Lakshminrusimha S, Pearlman SA, Raju T, Gallagher PG, Mendlovic J. Perinatal aspects on the covid-19 pandemic: a practical resource for perinatal-neonatal specialists. J Perinatol 2020;40(05):820-826

55 Rawat M, Chandrasekharan P, Hicar MD, Lakshminrusimha S. COVID-19 in newborns and infants-low risk of severe disease: silver lining or dark cloud? Am J Perinatol 2020;37(08):845-849

56 Chandrasekharan P, Vento M, Trevisanuto D, et al. Neonatal resuscitation and postresuscitation care of infants born to mothers with suspected or confirmed SARS-CoV-2 infection. Am J Perinatol 2020;37(08):813-824

57 Gonzalez-Brown VM, Reno J, Lortz H, Fiorini K, Costantine MM. Operating room guide for confirmed or suspected COVID-19 pregnant patients requiring cesarean delivery. Am J Perinatol 2020;37(08):825-828

58 Stephens AJ, Barton JR, Bentum NA, Blackwell SC, Sibai BM. General guidelines in the management of an obstetrical patient on the labor and delivery unit during the COVID-19 pandemic. Am J Perinatol 2020;37(08):829-836

59 Breastfeeding guidance post hospital discharge for mothers or infants with suspected or confirmed SARS-Co V-2 infection. Available at: https://services.aap.org/en/pages/2019-novel-coronavirus-covid-19-infections/clinical-guidance/breastfeedingguidance-post-hospital-discharge/. Accessed on June 18, 2020

60 Evaluation and management considerations for neonates at risk for COVID-19. Available at: https://www.cdc.gov/coronavirus/2019ncov/hcp/caring-for-newborns.html. Accessed on June 18, 2020

61 NPC-19 Registry Update (National Registry for Surveillance and Epidemiology of Perinatal COVID-19 Infection). Available at: https://my.visme.co/view/ojq9qq8e-npc-19-registry. Accessed on June 18, 2020 